Acta Hispanica (2018) 23: 189-199

\title{
ZURITA Y UNA POESÍA TOTALITARISTA
}

\section{ENIKŐ MÉSZÁROS}

\author{
Universidad de Szeged
}

\begin{abstract}
Resumen: La persona de Raúl Zurita, poeta chileno del siglo XX, significa, prácticamente, una manifestación artística que sobrevivió la dictadura de Pinochet. Su obra parece ser una memoria viva y presente de aquella época. A pesar de ser conocido principalmente como poeta, sus actos se realizan en el campo de diferentes ramas artísticas. Su poesía toca las piedras del desierto de Atacama y crea letras de nube en el cielo, mientras se conecta con las ramas de la fotografía y de la música también. El presente trabajo formula la cuestión de qué papel desempeñó toda la actividad artístico-poética de Raúl Zurita en el contexto cultural y político-social chileno. Para llegar a sacar conclusiones hace falta meditar en la importancia de la fusión de las diferentes ramas del arte, pero también en la naturalidad con la que el arte se incorpora en la vida cotidiana. $\mathrm{El}$ arte de Zurita, en cierto sentido, no es menos totalitarista (o totalitaria) que el régimen militar, el contexto que lo generó, aunque representan dos polos completamente opuestos.
\end{abstract}

Palabras clave: Zurita, arte, acciones, totalitarismo, Chile

\begin{abstract}
The persona of Raúl Zurita, the 20th century Chilean poet, practically means an artistic manifestation which survived through the dictatorship of Pinochet. His work appears as a vivid memory of that period. Despite of being known principally as a poet, his accomplishments are actualized in different artistical fields. His poetry touches the stones of the Atacama Desert and creates cloud-letters in the sky, while attaching to the photographical and musical areas. This paper proposes the question of what was the role of all the artistic-poetic activity of Raúl Zurita in the cultural, political and social context of Chile. To draw any inference, it is needed to retrace the importance of the fusion of different artistical fields along with the enquiry of how naturally art incorporates into the everyday life. In a certain sense, Zurita's art is not less totalitarist (or totalitarian) than the military regime itself which is the context have generated it, even if they represent two completely opposite poles.
\end{abstract}

Key words: Zurita, art, actions, totalitarism, Chile

Y cuando vengan a desplegarse los paisajes convergentes y divergentes del Desierto de Atacama Chile entero habrá sido el más allá de la vida porque a cambio de Atacama ya se están extendiendo como un sueño los desiertos de nuestra propia quimera allá en estos llanos del demonio.

(Zurita, Raúl. Purgatorio. El desierto de Atacama VI, 1979) 
Raúl Zurita es, antes que nada, autor de las obras Anteparaíso, La vida nueva, Canto a su amor desaparecido e INRI. Vivió y sobrevivió en constante actividad artística la dictadura de Augusto Pinochet, siendo uno de los motores medio-escondidos y poco documentados (y por eso demasiado poco conocidos) de los movimientos de la Escena de Avanzada del postgolpe. Es Doctor Honoris Causa de la Universidad de Alicante y ganador de varios premios de poesía: Premio Pablo Neruda, Premio Nacional de Literatura o Pericle d'Oro de Italia.

Sin embargo, la presentación introductoria del chileno Raúl Zurita no se agota en hablar sobre él solamente en su calidad de poeta en el sentido moderno. La manifestación de su poiesis no se limita a las palabras impresas en hojas de papel ni insiste únicamente en la lectura cotidiana. Su área de actuación y la de la repercusión de sus actuaciones tampoco se encajan exclusivamente dentro de los enfoques del campo literario-académico. Zurita es uno de los poetas de este siglo que parece percibir con plena naturalidad y por puro instinto las raíces y aquel núcleo original de la poesía que en tantos momentos de la historia de ésta - por diversas razones- se ha visto obligado a relegarse al segundo plano. Su obra vuelve el camino de la poesía hacia una función más viva y poderosa que comprende representación, acto creativo y fabricación (a veces en un sentido hasta más técnico), hacia una función más efectiva debido a la complejidad de las formas, los recursos, los medios o los modos de sus manifestaciones.

Resulta ser necesario completar, entonces, la introducción a tal poesía con la presentación de Zurita como artista, y anunciar un proyecto poético que en algunas ocasiones llega a exceder los límites de la textualidad. Zurita es creador de una poesía que se cumple antes que nada en la vida y no en la literatura, o por lo menos no solo en la literatura. Por lo que se refiere a sus acciones individuales, una de las más conocidas viene del año 1982 cuando unos versos suyos fueron escritos en el cielo de Nueva York por quince aviones (La vida nueva), proponiendo así al público una lectura colectiva, fugaz e irrepetible, desde la tierra. En 1993 mandó grabar el texto Ni pena ni miedo en la superficie del desierto de Atacama, un verso-mensaje leíble solo desde el cielo, mientras su obra Diálogo con Chile, Escritura en los acantilados, fue una realización artística de tres kilómetros de longitud a lo largo de las Cordilleras, visible exclusivamente desde el océano. Junto a sus acciones de tipo land art (con las que rodeó así poéticamente el Chile geográfico-natural desde diferentes espacios), se recurrió también al uso de su propio cuerpo como materia de arte: se hirió la cara y echó amoniaco en los ojos. 
Entre mi mejilla quemada y los textos pasa un modo de la realidad. Romper con las fronteras que parcelan la creatividad y hacen que el pintor haga cuadros, el poeta poemas, el cineasta cine; es un asunto capital, es un asunto revolucionario, romper esas barreras significa hacer que la vida misma, desde las acciones más simples, que sé yo, tomarse una taza de café, hasta las operaciones mentales más complejas, decía, es hacer que el acto mismo de vivir devenga un acto creativo. Es eso lo que importa (Brito, 1980).

La necesidad de tal interpretación del acto creativo se veía intensificando después de los primeros años de paralización de las actividades individuales y a grupos causada por el golpe militar de 1973. Cualquier movimiento contestatario debió plantearse en una zona abierta, pública y fácilmente accesible, ajeno del patrocinio de cualquier institución oficial, recurriendo al uso de formas indirectas. En la lenta y prevenida aparición de actos contestatarios de este tipo, el grupo artístico CADA (1979) tuvo un papel definitivo. El poeta Raúl Zurita, el sociólogo Fernando Balcells, la escritora Diamela Eltit y los artistas visuales Lotty Rosenfeld y Juan Castillo se unieron con el fin de realizar actos artísticos contestatarios. La misión del grupo era verbalizar y visualizar discursos que estaban prohibidos u obstaculizados debido a la opresión del poder autoritario, pero obstaculizados también como resultado de la consolidación de una sociedad dirigida por el consumo y el mercado. Tan como estos dos fenómenos iban ejerciendo influencia y presión sobre la sociedad paralelamente, a la hora de proyectar entablar nuevas posibilidades de dirigirse a la realidad circundante, estos dos factores se deben tomar en consideración en primer lugar.

Ahora bien, con la implantación del régimen militar se emergió en los años setenta una cultura autoritaria en Chile haciendo uso de intervenciones de control (censura), supresiones y modificaciones en los campos de la educación, la ciencia y en el de los medios de comunicación, entre otros. El subcampo del arte también sufrió restricciones y administración del poder. Aludiendo a Brunner-Barrios-Catalán (1989), en vez de que los grupos o las instituciones artísticas se vieran obligados a asumir una cierta orientación de propaganda del régimen, lo que pasó en la práctica fue que el Gobierno Militar tendía más bien a congelar la actividad cultural, cortando de esta manera el funcionamiento de cualquier efecto capaz de movilizar críticas y conflictos en el juicio de la sociedad. En estos primeros años de la instalación del régimen, entonces, el 
subcampo artístico paralizado perdió peso, sufrió una desvalorización de innovaciones y una marginación general.

La promesa de la modernidad planteada ya en los años sesenta durante la presidencia de Eduardo Frei Montalva se profundizó para los años setenta, y como consecuencia, el fenómeno de la cultura de masas -víctima de "las ideologías livianas, de los espectáculos de consumo masivo, de la trivialización de lo serio y de la banalización de lo sagrado" (Brunner-Barrios-Catalán, 1989)- iba alojándose y extendiéndose en el contexto chileno. El campo cultural se iba distanciando más y más desde el servicio público hacia una función del mercado, y el acceso a la cultura digamos más prestigiosa iba siendo un asunto más individual. Perdiendo la conexión con el público grande, el arte perdió "su vitalidad discursiva, su pluralidad, su apertura." Como resultado de estar en una subordinación funcional al régimen, la cultura que se somete al mercado, deja de cultivar el discurso, deja de tener densidad comunicativa que antes era su rutina, su función integrativa, así ya no es capaz de generar tensiones, debates, antagonismo, simplemente vota por una actitud afirmativa para satisfacer el intercambio de valores, la producción y la apropiación.

Esta naturaleza afirmativa y una sensación de incapacidad caracterizan la sociedad chilena en su actitud hacia las atrocidades frecuentes (digamos cotidianas) cometidas por el control del poder también. Zurita mismo menciona como ejemplo el hecho de cuánto se vuelven cotidianas las detenciones en las calles de Santiago, a lo que la gente simplemente reacciona tratando de mirar en otra dirección, tratando de no darse cuenta. El miedo inicial se va tornando en algo habitual:

\footnotetext{
Detenerse a mirar largo rato a algo o a alguien podía ser sumamente peligroso. Siempre había un terror colectivo de estar mirando algo. Eso partía de las detenciones de la gente en la calle. Las detenciones pasaban a plena luz del día a calle llena y nadie quería mirar eso, como entraban a un tipo a la fuerza en un auto. Nadie quería mirar nada (Neustadt, 2001:80).
}

Pero la misma actitud de incapacidad (y hasta indiferencia) se manifiesta en un ejemplo tan simple también como es el caso de la televisión (Brunner-BarriosCatalán, 1989), el caso del ideal "vehículo poderoso de expansión" que participa intensamente en convertir la comunicación diaria en una transmisión unilateral, 
y a la gente en objetos mudos e incapaces de formular cualquier tipo de cuestión o de hacer una más mínima intervención.

Muy difícilmente es evocable en tal contexto anti-humano la pasada vida artística chilena de los años cincuenta que parecía ser un campo mucho más valiente. Nelly Richard rememora este pasado aludiendo a las palabras de Pablo Oyarzún:

\begin{abstract}
Una mirada sobre el desarrollo artístico nacional señala como la evolución del arte en Chile, desde fines de los 50, puede ser descrita como una serie de modernizaciones tendiente a constituir una modernidad del arte, consciente de sí misma y organizada [...] como campo de indagaciones y ejecuciones que busca incidir en todos los nudos del circuito de producción artística; en la obra, en el productor, en el público, en las relaciones múltiples entre ellos, en la fijación institucional de esas relaciones, en las determinaciones del arte mismo y de su nexo con lo real (Richard, 1994:37).
\end{abstract}

A finales de los años setenta, entonces, Zurita y el grupo CADA, con frecuencia utilizando los recursos y tecnología más novedosos ( $\mathrm{y}$-por lo que a veces les tocan las críticas negativas- costosos), empiezan a actuar realizando sus acciones artísticas que también estaban vinculadas a las corrientes de neovanguardia. De la especificación de estos actos (trayendo algunos ejemplos concretos) me ocuparé más adelante a la hora de detallar la respuesta artística de Raúl Zurita y el grupo CADA a las necesidades de la realidad socio-cultural y política.

Uno de los pasos que se da mediante tales movimientos en Chile, entonces, es prácticamente abrir camino para el proceso de una refuncionalización de la cultura. La pasividad de interactividad de la sociedad, la falta de sentido de los signos (fenómeno proveniente de la quiebra histórico-política) deben ser perturbadas, agitadas según los nuevos proyectos artísticos. La nueva misión es, por consecuencia, producir interferencias críticas dentro de la sociedad, por un lado. Por otro lado, se debe tener en cuenta el razonamiento de Nelly Richard (1987) sobre los signos y el sujeto interpretante. Puesto que entre las muchas formas de fractura que el golpe causó, ocasionó "la fractura de todo el marco de experiencias sociales y políticas que lo había antecedido, desintegró también los modelos de significación configurados por el lenguaje que nombraba esas experiencias." Se produjo una fracción en -sigo refiriéndome a Nelly Richardlos nexos entre el signo (aparentemente seguro y permanente) y su conciencia interpretante. Se perdió la confianza del sujeto a la hora de interpretar los signos 
porque estos signos, estos códigos habían sido fundados en ilegitimidad y estaban sufriendo falsificaciones y errores. La noción del sujeto se encontraba en una dislocación. De ello se deduce la tarea más concreta de la misión que resulta ser reformar los enlaces entre la noción del sujeto y los signos, recurriendo a la aplicación de una fuerza creativa rompedora, y para eso extremar las condiciones y las límites de la práctica del arte, mientras teniendo en cuenta que todo el proyecto debe pretender alcanzar al mayor público posible. Será el restablecimiento de tales enlaces, por lo demás, que surtirá, o mejor dicho, devolverá -según las expectativas- las visiones críticas y la formulación de diálogos a la sociedad.

Tales acciones poético-artísticas contribuyen -entre otras cosas-a la posibilidad de la introducción de nuevas interpretaciones de la historia y política chilenas, diferentes de las oficiales. Esto no significa necesariamente una relevación o la proclamación de una verdad, sino la capacidad de formular nuevos discursos. La comprensión de esto nos reconduce al reconocimiento de la antigüedad y de la naturalidad del arte (y de la poesía). La concepción del arte, según Zurita, no tiene nada que ver con la verdad y la no verdad, porque el hecho poético es mucho más arcaico y crucial en la constitución de lo humano que el asunto de la verdad (Zurita, 2013, 44:30). Aludiendo a las palabras del poeta, el hecho poético nace con lo humano en el momento en el que uno entiende que debe morir, y de ello viene que toda obra de arte es una rememoración del primer encuentro primigenio con aquella irremediabilidad que es la muerte. Resumiendo otra vez la importancia de la aportación a la vida cotidiana de la formulación de nuevos y diferentes discursos: la brecha intermediaria entre las verdades se entiende como una nueva topología de lo real, algo que los artistas como Zurita deben rediseñar (Richard, 1987).

El presente trabajo no se concentra en la profundización de ninguna de las ramas de la complejidad de la obra de Raúl Zurita en especial, sino que, dibujando un panorama que abarca toda la vasta y multilátera actividad del poeta, busca identificar las características propias de su actitud artística que responden a los problemas socio-culturales de la época (arriba planteados). Dentro de este panorama caben: sus poemas y fotos impresos, sus acciones individuales (que comprende sus acciones body art, land art, filmaciones etc.) y las acciones llevadas a cabo por él junto a sus compañeros del grupo CADA, incluidas a esta lista todas las huellas y memorias de las acciones expuestas en exhibiciones. La cuestión es cómo responden todas sus obras a los problemas y dificultades circun- 
dantes, y en total qué papel juega Raúl Zurita en aquel empuje de fondo que conduce a los cambios significativos en la actitud de la sociedad chilena de los años ochenta.

Partiendo simplemente de los poemas textuales impresos de Zurita, éstos en sí también sirven el objetivo de devolver la capacidad de discurso a la sociedad, mediante los artificios literarios externos heredados de la vanguardia. (El hecho de haber heredado tales instrumentos poéticos hace claro que la necesidad actual cae en "devolverle" esta capacidad a la gente y no "introducirsela", o sea, se revela la dimensión de la fractura.) Tales artificios provocan la interacción o por lo menos una cierta actividad mental por parte del lector: la ruptura de la sintaxis, los espacios blancos, el juego con las diferentes tipografías, las múltiples formas de codificación, el aislamiento inesperado de algunas palabras y otras irregularidades de fragmentación, la incorporación de signos matemáticos en los textos, el empleo del diálogo o la sugerencia de algún orden mediante fórmulas escritas en el estilo de proposiciones lógicas (Alemany Bay, 2011).

La importancia de la concepción visual queda reforzada, por lo demás, en la zona extraverbal también, mediante fotografías adicionadas a las páginas de los libros del poeta. El uso de las nuevas tecnologías (por ejemplo el del electroencefalograma o del vídeo) a la hora de exponer su poesía también sirve el traspaso de las fronteras tradicionales. La paleta de los recursos se enriquece con la introducción del cuerpo humano y los elementos naturales del paisaje como medios o materiales de obra, con el que se empieza a percibir la atenuación de la distancia entre el sujeto observador y el objeto observado hasta no poder hablar de observación. Iván Carrasco Muñoz detalla en sus artículos la expansión del significante como técnica primordial del proyecto poético de Zurita.

\footnotetext{
El lector no se encuentra, así, con un panorama que debe observar, sino inmerso en una situación comunicativa estética en la que debe participar, aportando sus vivencias, sus conocimientos, su sensibilidad, su compromiso (Carrasco Muñoz, 2014).
}

Por lo que se refiere a los elementos naturales de Chile, optar por extender su poesía sobre el cielo, el desierto, el océano, las montañas y los llanos del país, éstos, en su grandiosidad y desmesura, más allá de su papel de generar comunicación y establecer conexión con la colectividad, también son símbolos de resistencia y firmeza, de supervivencia. Por encima (y entre paréntesis), sirven la continuación de la tradición poética chilena presentada por Gabriela Mistral y 
Pablo Neruda, entre muchos. Tal poder y expansión en la poesía bloquean la persistencia del contexto neutralizado postgolpista.

El espacio último pero quizás más significativo en la actividad de Zurita es el espacio urbano. Las acciones artísticas reocupan las calles y escogen a la gente ordinaria de la calle para ser colaboradora en las situaciones artísticas. El arte (la poesía) llevado fuera al espacio público es un paso particularmente significativo a la hora de intentar entablar una comunicación efectiva con las masas. Vale la pena tomar como ejemplo el poema La vida nueva escrito en el cielo de Nueva York por aviones. Tal poema es la conclusión, la etapa final del libro de Zurita que lleva por título Anteparaíso. El poeta mismo lo declara ser la conclusión de su libro, mientras se retira de la idea de creerse el único creador la obra:

salvo que no la escribiré yo. Fíjate, es eso lo que te he querido decir, la obra individual se disuelve en el trabajo de producción social, concreta, de un nuevo espacio en que cada uno habrá de asumir la propia vida y la de todos como el único producto de arte que merece ser sociabilizado. Es eso lo que llamo "Paraíso" [...] el Paraíso no lo escribo yo ni tú (Brito, 1980).

Nelly Richard acerca el fenómeno a la idea de la utopía vanguardista que soñaba con romper los muros entre arte y vida, con cortar el poder del exclusivismo del campo artístico, un exclusivismo que -situándose en el contexto dictatorial chileno- habría perdido, en todo caso, todas las oportunidades de funcionamiento libre.

\footnotetext{
Para romper la clausura del adentro (los intramuros) del arte y lograr la finalidad vanguardista de su incorporación al afuera de la vida, es necesario abolir las divisiones que incomunican el arte: los muros de una sala $=$ el encierro del arte y la institución como cierre. Para que «arte» y «vida» intercambien sus signos horizontalmente, hace también falta anular los rasgos de superioridad y excepcionalidad que distinguen (remarcan $y$ favorecen) el significado privativo del arte (Richard, 1994:37).
}

El grupo CADA sigue exactamente una actuación artística callejera, vagabunda. Sus artistas van trabajando constantemente en el confín de lo posible, esforzándose para hacer caso mientras no quedando castigados. Están siempre llevados por la belleza y acompañados por el miedo. CADA es un grupo artístico que reconoce que no se puede responder al contexto circundante con un solo 
poema. Sus creaciones deben ser tan contundentes como la violencia y el daño que se hallan en su alrededor. Según Zurita, con los actos de CADA toda la dimensión del drama chileno emerge (Zurita, 2013, 11:20).

Llegando a estas reflexiones, gradualmente se ha dibujado lo que yo llamaría una poesía totalitarista. La palabra totalitarista también debe estar vinculada necesariamente a lo totalitario que es el régimen, bajo cuyo poder este tipo de arte funciona. Me parece oportuno hacer una contra-aplicación de la palabra y explicar la yuxtaposición de dos intervenciones que de alguna manera son semejantes en su funcionamiento, dos intervenciones que penetran con fuerza en la vida cotidiana de la sociedad: la intervención del régimen autoritario y la del arte que está actuando en las calles y cuya influencia es imposible evitar.

Esta contra-aplicación parece ser, básicamente, la técnica de Zurita y del grupo CADA. En sus diferentes acciones artísticas hacen uso de unas figuras, ocurrencias reales pasadas, imágenes que generalmente suelen ser atribuidas a las manifestaciones de poder del régimen. A lo largo de la acción denominada "Para no morir de hambre en el arte" (1979), por ejemplo, el proceso de repartir sacos de medio litro de leche entre la gente (clara alusión al proyecto de Salvador Allende) se realiza mediante un desfile de camiones lecheros, fenómeno indudablemente parecido al desfile de tanques. El caso de la acción, "¡Ay, Sudamérica!" (1981), el bombardeo de volantes artísticos por aviones inevitablemente evoca el día del bombardeo del Palacio de la Moneda. Las figuras son semejantes, el efecto, diferente. No se sabe qué saldrá de los camiones o qué caerá de los aviones, de todas maneras uno debe estar preparado para el miedo.

En cambio, el desenlace fue en ambos casos algo impredecible, nadie esperaba ni sacos de leche ni volantes artísticos. Lo que pasó es que CADA consiguió esconder nuevos significados detrás de los signos que eran considerados propios del discurso autoritario, con el fin de provocar un efecto chocante, una sorpresa. El resultado de tal truco conllevaba no solo la apertura hacia nuevos discursos sino una preparación para la disolución futura de la espera constante del terror también. Por lo demás, la fusión aún más clara entre las acciones artísticas y la situación política se nota en el acto "No+" que se prolonga hasta convertirse para el Plebiscito de 1989 en la consigna de la campaña de la oposición. 
Así que creo que el efecto fue más bien en otro orden. Las acciones del CADA tuvieron un gran poder. Eran las primeras acciones que se hacían pública y masivamente. Pública y masivamente porque implicaban todo lo que rodeaba: las detenciones, el miedo, el silencio (Neustadt, 2001:80).

Formulando las palabras de clausura, podemos decir que la obra de Raúl Zurita, en su totalidad, contribuyó en gran parte al empuje de importantes cambios político-sociales y culturales en Chile. Con una poesía totalitarista alcanzó que el arte cobrara un carácter semejante al de la política a la hora de haber intentado intervenir en la vida de la sociedad, corregirla con todos los instrumentos y creatividad posibles. Totalitarista en el sentido de que, dirigiéndose a la colectividad, hacía esfuerzos para reocupar la totalidad de las esferas de la vida para dar una nueva significación a la cotidianidad.

\section{Bibliografía:}

Alemany Bay, Carmen. 2011. "La forma externa del poema en la poesía chilena: de la vanguardia a los albores del siglo XXI" América sin nombre, 16. 54-62. Fecha de consulta: 31 de enero de 2018. Asequible en: https://rua.ua.es/dspace/ bitstream/10045/20639/1/ASN_16_06.pdf

Brito, María Eugenia. 1980. "Conversación con Raúl Zurita" Revista APSI, 16-29 de diciembre. Fecha de consulta: 31 de enero de 2018. Asequible en: http://www.letras.mysite.com/zurita1212.htm.

Brunner, José Joaquín - Barrios, Alicia - Catalán, Carlos. 1989. Chile. Transformaciones culturales y modernidad. Facultad Lainoamericana de Ciencias Sociales. Santiago de Chile: Editorial Salesianos.

Cánovas, Rodrigo. 1986. "Zurita Chilensis: Nuestro dolor, nuestro esperanza." Libn, Zurita, Ictus, Radrigán: Literatura cbilena y experiencia autoritaria. Facultad Latinoamericana de Ciencias Sociales. Santiago de Chile: Ediciones Ainavillo. 57-93.

Carrasco Muñoz, Iván. 2014. "El proyecto poético de Raúl Zurita". Fecha de consulta: 31 de enero de 2018. Cervantesvirtual. Asequible en:

http://www.cervantesvirtual.com/obra-visor/el-proyecto-poetico-de-raulzurita/html/13553b2b-588d-4c88-acea-787f18c8676a_2.html.

Neustadt, Robert. 2001. CADA DÍA: la creación de un arte social. Cuadernos de análisis y debates culturales. Santiago de Chile: Editorial Cuarto Propio. 
Richard, Nelly. 1987. "Márgenes e institución. Arte en Chile desde 1973.” Nelly Richard (coord.). Arte en Chile desde 1973. Escena de Avanzada y sociedad. Facultad Latinoamericana de Ciencias Sociales. N. ${ }^{\circ} 46$. Santiago de Chile: Contribuciones Programa FLACSO-Santiago de Chile. 1-17.

Richard, Nelly. 1994. La insubordinación de los signos (cambio politico, transformaciones culturales y poéticas de la crisis). Santiago de Chile: Editorial Cuarto Propio.

Zurita, Raúl. 2013. "Recuerdos y reflexiones de Raúl Zurita". Fecha de consulta: 31 de enero de 2018. Vídeo en Youtube. Cervantesvirtual. Universidad de Alicante. Asequible en: https://www.youtube.com/watch?v=Y3P-mJ0K9Kk.

Zurita, Raúl. 1979. Purgatorio. Santiago de Chile: Editorial Universitaria. 